\title{
SINAES: Perspectivas e desafios na avaliação da educação superior brasileira
}

\author{
Marlis Morosini Polidori \\ Claisy M. Marinho-Araujo \\ Gladys Beatriz Barreyro
}

\section{RESUMO}

A partir da década de 90, o Brasil desenvolveu diferentes estratégias de avaliação da educação superior, começando pelas universidades públicas. Surgiu o PAIUB (1994) que se caracterizou como um Programa construído pelas IES, com o objetivo de desenvolver um processo de avaliação institucional. Em 1996, foi introduzido o Provão, seguido de outros mecanismos avaliativos com a proposta de nivelar as IES em termos de qualidade que, no entanto, não atendeu aos objetivos. Este trabalho recupera essas experiências e traz subsídios sobre a construção e a implantação do Sistema de Avaliação da Educação Superior Brasileiro - SINAES, sancionado em 2004, discutindo os desafios e perspectivas decorrentes de sua implementação.

Palavras-chave: Avaliação da educação superior. Avaliação institucional Educação superior. Políticas educativas.

\section{ABSTRACT \\ SINAES: perspectives and challenges in evaluation of Brazilian Higher Education system}

Since 1990, Brazil has developed many different strategies to evaluate higher education, beginning with public institutions. In 1994, the Program of Institutional Evaluation of Brazilian Universities - PAIUB, was created by the Higher Education Institutions - IES, aiming at developing an institutional evaluation process. In 1996, the Provão was introduced, followed by other evaluation mechanisms with the objective of leveling the IES in terms of quality which, in fact, did not happen. This paper brings these experiences back and adds subsidies about the building up and implementation of the Brazilian National Higher Education Evaluation 
System - SINAES, sanctioned by law in 2004, discussing the challenges and perspectives arising out of its implementation.

Keywords: Evaluation of higher education. Institutional evaluation. Higher education. Educational policies.

\section{RESUMEN}

\section{Señales: Perspectivas $y$} desafios en la evaluación de la educación superior brasileña

A partir de la década de 1990, Brasil desarrolló diferentes estrategias de evaluación de la educación superior, comenzando en las universidades publicas. Surgió el PAIUB (1994) que se caracterizó como un Programa construido por las propias Instituciones de Educación Superior (IES), con el objetivo de desarrollar un proceso de evaluación institucional. En 1996, fue implementado el "Provão", seguido de otros mecanismos evaluativos con la intención de nivelar la calidad de las IES, aunque no cumplió esos objetivos. Este trabajo recupera esas experiencias e incorpora informaciones sobre la construcción y la implantación del Sistema de Evaluación de la Educación Superior Brasileña (SINAES), sancionado en 2004, discutiendo los desafios y perspectivas que surgen a partir de su implementación.

Palabras clave: Evaluación de la educación superior. Evaluación institucional. Educación superior. Políticas educativas.

\section{INTRODUÇÃO}

Historicamente, a avaliação da educação superior no país tem início na década de 70, com a instituição da política de avaliação da pós-graduação pela CAPES, especialmente voltada aos cursos de mestrado e doutorado.

No âmbito da avaliação dos cursos de graduação, datam de 1983 as primeiras idéias sobre o tema, com a instituição, pelo Ministério da Educação -MEC, do Programa de Avaliação da Reforma Universitária - PARU, que enfatizava a gestão das Instituições de Ensino Superior - IES, a produção e a disseminação dos conhecimentos. Desativado no ano seguinte, tal programa foi substituído por várias iniciativas governamentais, como a constituição da "Comissão de Notáveis" em 1985, e do Grupo Executivo da Reforma da Educação Superior - GERES, em 1986.

Entre o final da década de 80 e início dos anos 90, algumas universidades iniciaram experiências de auto-avaliação, que contribuíram para criar um espaço de interlocução entre o MEC e as instituições federais, representadas pela Associação das Instituições Federais do Ensino Superior -ANDIFES. Pela mediação da ANDIFES, as experiências de auto-avaliação subsidiaram a construção do Programa de Avaliação Institucional das Universidades Brasileiras - PAIUB, que teve o apoio da SESu/MEC, de 1993 a 1994.

Em 1996, foi introduzido, em âmbito nacional, o Exame Nacional de Cursos - ENC, popularizado como "Provão", seguido de outros mecanismos avaliativos, tais como a Avaliação das Condições de Ensino - ACE, e a Avaliação para credenciamento de IES privadas, com a proposta de nivelar as insti- 
tuições em termos de qualidade. No entanto, este modelo mostrou-se insuficiente e fragmentado para responder ao questionamento referente ao tipo de educação superior que era oferecido aos brasileiros.

A partir disso, foi desencadeado um processo de discussão que, como resultado, originou o Sistema Nacional de Avaliação da Educação Superior - SINAES, com a proposta de ser, realmente, um sistema integrador, que garantisse informações e análises da totalidade da educação superior permitindo, assim, que políticas educativas fossem instaladas tanto em nível nacional pelos órgãos pertinentes quanto em âmbito institucional, articuladas pelas IES.

Serão discutidas, a seguir, as citadas estratégias desencadeadas no país para sustentar a avaliação da educação superior.

Revisitando a história da avaliação da educação superior no país: o Programa de Avaliação Institucional das Universidades Brasileiras

Programa de Avaliação Institucional das Universidades Brasileiras _PAIUB, foi a primeira tentativa de implantação de um sistema nacional de avaliação institucional da educação superior no país. Este Programa foi criado oficialmente em 1993, e caracterizou-se como uma resposta ao movimento realizado pelas universidades públicas brasileiras, referente ao desafio de implantar um sistema de avaliação institucional que fosse centrado na graduação. O PAIUB, contando com a adesão voluntária das IES, caracterizou-se como um Programa construído pelas mesmas, com o objetivo de desenvolver um processo de avaliação institucional valorizando as especificidades de cada instituição.

Na ocasião, o enfoque seria o ensino de graduação, de pós-graduação e de extensão buscando atender aos objetivos de aperfeiçoamento da qualidade acadêmica, com ênfase nos cursos de graduação; na melhoria da gestão universitária, gerando dados e diagnósticos confiáveis, e na prestação de contas à sociedade do desempenho das Universidades. No entanto, na maioria das IES que participou do PAIUB, somente a graduação desenvolveu algum trabalho. Evidencia-se que a pós-graduação estava sob o encargo de instituições financiadoras como a CAPES e o $\mathrm{CNPq}^{1}$, as quais, é importante ressaltar, desenvolveram uma tradição no campo da avaliação da pós-graduação.

Além disto, dentro de uma perspectiva de desenvolvimento de uma universidade contemporânea, o processo de avaliação deveria atender a três exigências básicas: ter um processo contínuo de aperfeiçoamento do desempenho acadêmico, atuar como uma ferramenta para o planejamento da gestão universitária e atender a um processo sistemático de prestação de contas à sociedade (BRASIL, 1994).

Neste quadro, o PAIUB foi estabelecido a partir da Comissão Nacional para Avaliação das Universidades Brasileiras, criada em julho de 1993. Nessa Comissão estavam representados vários órgãos e associações de diferentes setores da educação superior, com a intenção de desenvolver um trabalho de análise e discussão através de propostas advindas destes mesmos setores. No entanto, somente a Associação Nacional dos Diri-

' CAPES - Coordenação de Aperfeiçoamento de Pessoal de Nível Superior; CNPq - Conselho Nacional de Desenvolvimento Científico e Tecnológico. 
gentes das Instituições de Ensino Superior - ANDIFES, produziu um Guia para Avaliação Institucional, que foi, mais tarde, adotado na implantação do PAIUB. O Programa foi elaborado seguindo os princípios de: globalidade, comparabilidade, respeito à identidade institucional, não-premiação ou punição, adesão voluntária, legitimidade e continuidade do processo de avaliação.

$\mathrm{Na}$ proposta de atingir os objetivos de promover a permanente melhoria da qualidade da educação superior, o Programa era dividido em quatro etapas:

19 - Diagnóstico: construído a partir de dados quantitativos sobre o curso em análise;

$2^{\text {a }}$ - avaliação interna: contemplando a auto-avaliação, realizada pela comunidade acadêmica do curso;

3a - avaliação externa: realizada pela comunidade acadêmica de várias IES, profissionais de áreas, representantes de entidades científicas e profissionais, e empregadores, entre outros;

4ㅁ - reavaliação interna: feita a partir dos resultados avaliativos produzidos, propiciando uma análise com a comunidade do Curso.

Quando de sua implantação, O PAIUB recebeu um financiamento por parte da Secretaria do Ensino Superior - SESu, do Ministério da Educação -MEC, e este foi colocado em prática ainda no ano de 1993, através de um edital. Outros dois editais foram publicados em 1994 e 1996, consolidando o processo. No entanto, em 1996, com a introdução do Exame Nacional de Cursos, por meio do Decreto n. ${ }^{\circ}$ 2026/96, houve uma reorganização da avaliação da educação superior. Nesta mesma ocasião, o financiamento antes designado foi retirado. Neste sentido, o PAIUB recebeu uma nova organização, mas não conseguiu manterse enquanto sistema de avaliação, e foi, literalmente, deixado de lado para dar espaço às estratégias de avaliação da educação superior que estavam sendo apresentadas.

\section{O Exame Nacional de Cursos - ENC - Provão}

Decorrentes da sanção da Lei de Diretrizes e Bases da Educação Nacional - LDB, $n^{\circ}$ 9394/96 (BRASIL, 1996b), que regulamenta a Constituição Federal de 1988 (BRASIL, 1999), especialmente nos artigos que permitem a diversificação dos modelos institucionais e estabelecem a validez limitada do credenciamento de instituições e reconhecimento de cursos, acontece uma rápida expansão do sistema da educação superior ${ }^{2}$ e, portanto, um desenvolvimento de estratégias de avaliação inseridas por várias legislações: Decreto 2026/96 (BRASIL, 1996a); Portaria 249/96 (BRASIL, 1996c); Decreto 3860/01 (BRASIL, 2001) dentre outras. As legislações propunham vários instrumentos avaliativos para verificar a qualidade do ensino superior oferecido no país.

Estes instrumentos seriam o Exame $\mathrm{Na}$ cional de Cursos, o processo de Avaliação das Condições de Oferta - ACO, que depois passou a ser chamado de Avaliação das Condições de Ensino - ACE, e, ainda, o processo de avaliação das IES para credenciamento e recredenciamento, no caso

\footnotetext{
${ }^{2}$ As matrículas se duplicam entre 1995 e 2002 (de 1.759.703 para 3.479.913) e, também, os cursos (de 6.252 para 14.339), sendo que esta expansão ocorreu pela via do setor privado. (INSTITUTO NACIONAL DE ESTUDOS E PESQUISAS EDUCACIONAIS ANÍSIO TEIXEIRA, 2003).
} 
de instituições privadas. No entanto, somente o Exame Nacional de Cursos, que ficou conhecido como Provão ${ }^{3}$, foi o instrumento utilizado para base de estruturação de políticas educativas. Os demais foram sendo desenvolvidos pontualmente e, principalmente, para atender a legislação referente a autorização, reconhecimento, renovação de reconhecimento de cursos de graduação e credenciamento e recredenciamento de IES.

O Provão constituiu-se como uma avaliação periódica anual das instituições e dos cursos de nível superior de graduação, e teve como função avaliar os conhecimentos e competências técnicas adquiridas pelos estudantes em fase de conclusão dos cursos de graduação. A prestação do Provão era condição obrigatória para a obtenção do diploma. Ele foi implantado em 1996, atingindo três áreas de conhecimento ${ }^{4}$, e vigorou até 2003 abrangendo 26 áreas de conhecimento de graduação do país ${ }^{5}$.

Importante salientar que o Provão desencadeou várias ações de modificação nas IES, desde a reformulação de currículos e formas de trabalho, devido às exigências previstas, até a criação de "cursinhos préprovão" que tinham como objetivo moldar os alunos ao formato do Provão. Esse exame sempre apresentou muita controvérsia em relação às suas conseqüências, pois, na verdade, os efeitos negativos se sobrepuseram aos positivos. $\bigcirc$ "Provão", na prática, foi um regulador não tradicional, mercadológico, "uma mão invisível", porque os resultados das provas aplicadas aos alu- nos foram utilizados, por deslocamento, como "notas" dos cursos e também como "notas" das IES, com grande cobertura da mídia (BARREYRO, 2003).

Quando da sua extinção, em 2003, no momento da divulgação do Relatório Técnico do Exame Nacional de Cursos daquele ano, a nova equipe do Instituto Nacional de Estudos e Pesquisas Educacionais Anísio Teixeira -INEP, órgão responsável pela operacionalização dos instrumentos avaliativos da educação superior, desenvolveu uma análise diferenciada que permitiu visualizar os reais resultados emitidos no Provão. Ou seja, foi possível verificar que os conceitos atribuídos às IES, até então publicados, divididos em uma escala de "A" a " $E$ ", significavam notas distorcidas. Para tal demonstração, foram divulgados, além dos conceitos absolutos, os conceitos relativos de cada curso. Foi possível verificar, portanto, que há instituições que obtiveram conceito " $\mathrm{A}$ " mas, na verdade, este " $A$ " significou, como no caso da matemática, uma nota igual a 29,4 em 2002 ou 34,7; em 2003. Ainda outros exemplos foram trazidos, tais como: a nota 46,3 em Administração era " $A$ "; já a nota 49,7 em Odontologia era " $D$ "; 50,0 em Engenharia Civil era "A", já 52,3 em Fonoaudiologia era " $\mathrm{C}$ "; 41,8 em Engenharia Elétrica era " $B$ "; já 44,1 em Agronomia era " $A$ "; 29,4 em Matemática era " $A$ "; já em Pedagogia 32,0 era "D" (INSTITUTO NAClONAL DE ESTUDOS E PESQUISAS EDUCACIONAIS ANÍSIO TEIXEIRA, 2003). Estas informações, de uma certa forma, causaram estranheza tanto da comunidade acadêmica, como da sociedade, pois, na verdade,

\footnotetext{
${ }^{3}$ A origem da palavra "provão" surgiu da União Nacional de Estudantes (UNE), que utilizou esta expressão para se opor ao ENC na tentativa de desqualificá-lo e o MEC utilizou-a positivamente. (POLIDORI, 2000).

${ }^{4}$ Administração, Direito e Engenharia Civil.

${ }^{5}$ Administração, Agronomia, Arquitetura e Urbanismo, Biologia, Ciências Contábeis, Direito, Economia, Enfermagem, Engenharia Civil, Engenharia Elétrica, Engenharia Mecânica, Engenharia Química, Farmácia, Física, Fonoaudiologia, Geografia, História, Jornalismo, Letras, Matemática, Medicina, Medicina Veterinária, Odontologia, Pedagogia, Psicologia e Química.
} 
o processo não tinha sido devidamente explicitado durante os oito anos de aplicação do Provão.

Esta era a realidade do sistema de avaliação da educação superior do país desenvolvida até 2003. Com o objetivo de mudar esta forma de olhar a educação superior, e na proposta de desenvolver um sistema amplo, integrado e que envolvesse as instituições de ensino superior na sua globalidade, foram realizados estudos e discussões na tentativa de se construir um sistema com estas características. Foi então que, em 2004, instituiu-se o SINAES.

\section{O Sistema Nacional de Avaliação da Educação Superior - SINAES}

A discussão sobre a criação de um novo sistema de avaliação da educação superior teve o seu início em abril de 2003, quando foi criada a Comissão Especial de Avaliação - CEA que, após realizar discussões com a comunidade acadêmica e com a sociedade civil organizada, produziu o documento intitulado "SINAES: bases para uma nova proposta de avaliação da educação superior" (BRASIL, 2004).

O SINAES fundamenta-se na necessidade de promover a melhoria da qualidade da educação superior, a orientação da expansão da sua oferta, o aumento permanente da sua eficácia institucional, efetividade acadêmica e social e, especialmente, o aprofundamento dos compromissos e responsabilidades sociais. Ele tem como objetivo assegurar o processo de avaliação das instituições de educação superior, dos cursos de graduação e do desempenho acadêmico de seus estudantes.
Este Sistema é acompanhado pela Comissão Nacional de Avaliação da Educação Superior, a CONAES, como um órgão colegiado de coordenação e supervisão do SINAES. Esta Comissão tem como função estabelecer os parâmetros gerais e as diretrizes para a operacionalização do sistema de avaliação. Evidencia-se que a operacionalização do Sistema está sob a responsabilidade do Instituto Nacional de Estudos e Pesquisas Educacionais Anísio Teixeira - INEP.

O Sistema foi instituído através da Lei $\mathrm{n}^{\circ}$. 10.861, de 14/04/2004 (BRASIL, 2004a), aprovada pelo Congresso e sancionada pelo Presidente da República, e encontra-se no seu processo de desenvolvimento, a institucionalização das Comissões Próprias de Avaliação - CPA, órgãos internos às instituições que devem coordenar os seus processos avaliativos foram instaladas dentro do prazo de exigência da lei; a CONAES foi constituída e vem organizando e coordenando o processo avaliativo; e o INEP está desenvolvendo todas as práticas avaliativas que lhe foram designadas.

Como forma de atingir as instituições de ensino superior na sua totalidade, o SINAES possui três componentes principais: a avaliação das instituições, dos cursos e do desempenho dos estudantes. Salientase que este modelo de avaliação tem como base a avaliação institucional, que compreende a avaliação externa e a avaliação interna, principalmente com seu componente central, a auto-avaliação.

Evidencia-se, portanto, que o ponto central da análise do presente trabalho está relacionado à importância da construção e da existência de um Sistema Nacional de Avaliação da Educação Superior no país. É fun- 
damental que o Sistema permita que as IES desenvolvam a sua gestão com base nas informações advindas deste processo de avaliação, e que, em última instância, os resultados provindos deste processo amplo de avaliação da educação superior sirvam como mecanismos para enriquecer o planejamento das IES e subsidiar a construção de políticas internas de desenvolvimento de oferta de um ensino superior de qualidade, além de subsidiar políticas públicas educativas.

Nesse sentido, é importante esclarecer como este Sistema se compõe e quais as suas intenções em relação à construção destas políticas educativas, tanto internas como externas.

Em seus princípios, o SINAES reconhece a diversidade do sistema de educação superior do país; respeita a identidade, a missão e a historia das instituições; entende que a as instituições devem ser avaliadas globalmente (ou seja, a partir de um conjunto significativo de indicadores de qualidade vistos em sua relação orgânica e não isoladamente), e, ainda, busca a continuidade do processo avaliativo.

O SINAES é composto por três eixos que compreendem a avaliação das instituições, dos cursos e dos estudantes.

primeiro eixo, que corresponde ao desenvolvimento da "avaliação das instituições", tem como principal objetivo verificar como as IES são constituídas, qual a sua capacidade de atendimento à comunidade acadêmica em todos os seus alcances e, neste item, está incluído um dos pontos mais importantes do sistema avaliativo: o desenvolvimento do processo de autoavaliação. A auto-avaliação busca, em primeira instância o auto-conhecimento, que favorece a construção de uma cultura da avaliação na instituição e permite também que as IES se preparem, de uma forma mais aprofundada, para as diversas avaliações externas a que são submetidas freqüentemente, principalmente através do processo de avaliação de cursos. No entanto, a intenção não é que a IES se adapte ao modelo de avaliação externa, mas sim, crie uma prática de avaliação e de reflexão imprescindíveis para o bom desenvolvimento de uma instituição de educação superior.

processo de auto-avaliação é o primeiro passo que compõe a avaliação interna, sendo que, na sua seqüência, é realizada uma avaliação externa por professores de outras IES do país, especialmente selecionados e capacitados para tal função. Esta fase é desenvolvida in loco por meio de visitas que têm como objetivo verificar informações disponibilizadas anteriormente, conhecer a IES, mas, sobretudo, auxiliar na construção de ações que possam vir a beneficiar o desenvolvimento do ensino oferecido pela IES.

Para tanto, o processo de auto-avaliação está atualmente sendo desenvolvido nas IES, orientado a partir da indagação de dimensões tais como: missão e plano de desenvolvimento institucional; políticas de ensino, pesquisa, pós-graduação e extensão; responsabilidade social da instituição; comunicação com a sociedade; políticas de pessoal; organização e gestão; infra-estrutura física, biblioteca, recursos de informação e comunicação; planejamento, avaliação e meta-avaliação; políticas de atendimento aos estudantes e egressos e sustentabilidade financeira. A proposta sugere a busca de informações sobre essas dimen- 
sões para examiná-las e analisá-las no interior das Instituições, com a participação dos seus atores, guiados pelas CPAs. Pretendese, assim, envolver na auto-avaliação a comunidade acadêmica para comprometêla nas descobertas, de forma participativa, com a finalidade de melhorar ou reforçar aspectos detectados pelas IES que sejam relevantes para os atores institucionais.

O segundo eixo se refere à "avaliação dos cursos de graduação". Esta é uma prática que já vinha sendo desenvolvida no sistema anterior; no entanto, para atender aos princípios do SINAES, adquiriu novas características, consistindo numa avaliação externa realizada por uma equipe multidisciplinar de especialistas para avaliar cursos de áreas afins, aos quais junta-se um avaliador institucional. Esse eixo terá sua articulação com os processos de regulação por estar definido na lei que os seus resultados estão vinculados com o reconhecimento e renovação (de reconhecimento) dos cursos.

Um outro aspecto importante é a capacitação dos especialistas, pois a intenção do sistema não é realizar ações de rastreamento, de perseguição, de policiamento ou de punição, mas, sim, proporcionar que as IES possam, com o auxílio de especialistas, dinamizar as suas atividades, resolver questões prementes e construir metas concisas e pontuais. Para tal, a capacitação, ou seja, as orientações dispensadas aos especialistas, devem ser de outra ordem além daquela que orienta a utilização de formulários eletrônicos e evidencia cumprimento de prazos. Apesar de estes pontos serem importantes, eles não podem ser os centrais de um processo avaliativo que busca a melhoria da qualidade da educação superior oferecida no país.
O terceiro e último eixo do SINAES compreende uma das participações mais importantes neste ambiente, a dos "estudantes". Inclusive, pode-se dizer que este elemento é um grande diferencial no Sistema. $\bigcirc$ diferencial diz respeito à mudança radical de como era apresentado o Provão, e principalmente, porque permite uma coleta rica de informações de tal forma a possibilitar às IES e às suas coordenações, a realização de debates e modificações nas suas questões acadêmicas com base em informações consistentes.

O principal instrumento de avaliação junto aos alunos chama-se Exame Nacional de Desempenho dos Estudantes - ENADE.

De acordo com a legislação vigente, no ENADE, a avaliação do desenvolvimento de conhecimentos, habilidades, saberes e competências, ao longo da trajetória vivenciada em cada curso, subsidia-se nas Diretrizes Curriculares, nas oportunidades de articulação teoria e prática, e no modo como as competências foram-se construindo, em função das relações partilhadas e dos contextos vivenciados.

As expectativas da formação na graduação incluem, para além do domínio de conteúdos, o desenvolvimento de posturas e processos que constituem o desenho de um perfil profissional esperado. Coadunadas a essas concepções, as Diretrizes Curriculares para os cursos de graduação no país, em sua grande maioria, elegeram o desenvolvimento de competências como meta orientadora na formação acadêmica, ainda que vinculado ao domínio de conhecimentos, saberes e práticas próprias da área profissional. A opção avaliativa do ENADE reflete essa ten- 
dência, ao privilegiar o desenvolvimento de competências ${ }^{6}$ entre os aspectos a serem avaliados, tendo como foco o processo no qual elas se constituem e a partir do contexto de ensino e aprendizagem no qual se configuram.

Para tal, o ENADE considera estratégias e instrumentos avaliativos diversificados, que consigam: a) investigar a forma como os estudantes estão conseguindo estabelecer a relação entre teoria, práticas, realidade e princípios éticos, na busca das competências; b) avaliar de que forma a produção teórica e o saber tácito tomam um novo significado quando mediados por processos socioculturais e relacionais; c) medir a integralização da dimensão reflexiva à ação, expressa nos atos ou no conjunto de atos, de opções, escolhas, compromissos (MARINHO-ARAUJO, 2004).

Este Exame é constituído por uma prova e um questionário socioeconômico.

O Questionário Socioeconômico (QSE) tem a função de compor o perfil dos estudantes, integrando informações do seu contexto às suas percepções e vivências. $O$ QSE, elaborado pelo INEP/MEC, investiga a percepção dos estudantes frente à sua trajetória no curso e na IES, por meio de questões objetivas que exploram a função social da profissão e os aspectos fundamentais da formação profissional.

ENADE é aplicado em grupos amostrais de alunos dos cursos de graduação que se encontram no final do primeiro e do último ano de formação.
A prova possui características bastante diferenciadas do que normalmente costuma-se trabalhar com alunos, bem como dos processos avaliativos que ocorrem durante a construção da vida escolar e acadêmica de cada um de nós, pois sua ênfase recai sobre as expectativas em relação ao perfil profissional que se deseja formar em cada curso. As perguntas da prova, de natureza objetiva e discursiva, priorizam temas contextualizados e atuais, problematizados em forma de estudo de caso, situações problemas, simulacros e outros, propiciando respostas por meio de múltipla escolha. A prova compõe-se de duas partes:

- A primeira parte, denominada Formação Geral, é um componente comum às provas das diferentes áreas aplicada a todos os cursos que participam do ENADE. Tem como objetivo investigar competências, habilidades e conhecimentos gerais que os estudantes já tenham desenvolvido no seu repertório, de forma a facilitar a compreensão de temas exteriores ao âmbito específico de sua profissão e à realidade brasileira e mundial.

- A segunda parte, denominada Componente Específico, contempla a especificidade de cada curso, tanto no domínio dos conhecimentos quanto nas habilidades esperadas para o perfil profissional. Essa parte investiga os conteúdos do curso por meio da exploração de níveis diversificados de habilidades e saberes em cada questão.

Todas as questões das duas partes da prova são elaboradas em níveis diferenciados de complexidade, permitindo que o estudante de $1^{\circ}$ ano, responda a várias questões, minimizando o risco de escolha de respostas a apenas algumas questões.

\footnotetext{
${ }^{6}$ Competência é entendida como um processo de ação reflexiva no qual são mobilizados recursos internos e externos (habilidades, capacidades, esquemas mentais, conhecimentos, saberes, posturas).
} 
Os padrões e referenciais mínimos para o Exame são definidos por Comissões Assessoras de Avaliação de Áreas e pela Comissão Assessora de Avaliação da Formação Geral. Compostas por especialistas de notório saber e atuantes na área, essas Comissões indicam competências, conhecimentos, habilidades e saberes a serem avaliados e demais especificações sobre a prova. É de responsabilidade dessas Comissões definirem diretrizes a serem observadas pelas bancas elaboradoras das provas.

ENADE tem um importante papel, tanto no processo de avaliação institucional, fornecendo subsídios para que as IES alimentem a dinâmica da auto-avaliação quanto na formulação de políticas públicas para o sistema de educação superior do país. Nesse sentido, - ENADE pretende proporcionar reflexão no interior do próprio curso e da instituição, na medida em que se constitui como um momento privilegiado de interlocução com os estudantes, visando a estimular a reflexão crítica e a avaliação de seus processos formativos.

O $1^{\circ}$ ENADE realizou-se, em todo o país, em 7 de novembro de 2004, avaliando treze áreas: Agronomia, Educação Física, Enfermagem, Farmácia, Fisioterapia, Fonoaudiologia, Medicina, Medicina Veterinária, Nutrição, Odontologia, Serviço Social, Terapia Ocupacional, Zootecnia (Portaria n 108/04).

Conforme prevista na legislação, a aplicação do ENADE ocorreu com grupos de estudantes dos referidos cursos, selecionados por amostragem, os quais se encontravam em momentos distintos de sua graduação: um grupo, considerado "iniciante", estando no final do primeiro ano; e outro grupo, considerado "concluinte", no final no último ano do curso. Os dois grupos de estudantes foram submetidos à mesma prova.
O delineamento amostral do ENADE foi operacionalizado de forma a contemplar instituições de todas as regiões do país, bem como de cada categoria administrativa e de cada organização acadêmica.

Q Questionário Socioeconômico abordou temas como perfil socioeconômico; oportunidades, atividades e programas acadêmicos; influência da mídia e de outras fontes de informação; avaliação das condições de ensino da instituição; contribuição das propostas pedagógicas; influência dos processos relacionais, entre outros.

Tendo em vista que o objetivo primordial do processo avaliativo defendido no ENADE é a identificação dos aspectos que precisam ser modificados e aperfeiçoados, essa primeira edição do Exame inaugura um novo momento no cenário da educação superior no país, pois sua ênfase é pedagógica. Os desdobramentos das análises e resultados poderão subsidiar redefinições político-pedagógicas aos cursos e percursos de formação, articulados com os demais elementos do sistema (avaliação institucional e avaliação dos cursos de graduação).

\section{Desafios e perspectivas}

O SINAES constitui-se em avanço de um modelo de avaliação da educação superior no Brasil, que promovia o ranking e a competitividade, baseado em estratégias de visibilidade mercadológica, para um paradigma que propõe a avaliação formativa ao incluir a autoavaliação participativa nas instituições e propor sua articulação com a regulação do sistema.

Esse sistema amplia o foco da avaliação ao incluir de forma integrada, as três dimensões: avaliação institucional, avaliação dos cursos e ENADE, não priorizando apenas o desempenho dos estudantes, permitindo, desta forma, 
mostrar uma imagem mais completa da qualidade da educação que está sendo oferecida.

Os desafios do SINAES são muitos e dependem de uma implementação fiel à proposta original favorecendo e fomentando o desenvolvimento dos processos formativos decorrentes da auto-avaliação. As informações e análises qualitativas nos três pilares vêm a beneficiar a difusão de uma cultura da avaliação que não se resume à construção de uma simples lista com o ranking de instituições. Embora o Sistema em si não facilite o ranking de instituições nem o Ministério o promova, o caráter público das informações prescrito pela lei e sua divulgação não favorecem e não impedem a realização de algum ranking na interpretação dos resultados.

Um outro desafio é a realização efetiva da auto-avaliação institucional. Embora já desenvolvida em várias IES públicas - nas quais foi possível que o processo fosse aprofundado - é sobretudo na maioria das instituições de pequeno porte, e principalmente nas privadas, nas quais a autonomia não se desenvolve de forma clara, que este processo está iniciando. Logicamente, vai depender do quanto as instituições se apropriem da proposta e dos seus resultados para que realmente se configure como um instrumento de gestão qualificado e não se converta apenas em um instrumento burocrático.

A grande quantidade de instituições e, principalmente, de cursos é um outro desafio para o sistema pela sua complexidade, pelas questões operacionais, especialmente nos aspectos regulatórios. $\bigcirc$ desafio é articular as necessidades regulatórias com os tempos requeridos à construção de uma cultura da avaliação nas instituições

Por fim, espera-se que o SINAES possa superar esses desafios e problemas, tendo em vista a implantação de uma lei aprovada após um processo de construção participativa que, além de ter considerado a história da avaliação da Educação Superior do país, incorporou suas principais experiências anteriores e as ressignificou (avaliação institucional, avaliação de cursos e exame aos estudantes) buscando atender aos objetivos propostos de uma avaliação ampla e participativa. Essa ação incluiu o Brasil entre os países que utilizam a avaliação institucional e confiam na participação e no compromisso de sua comunidade educativa como elemento alavancador para a melhoria da qualidade da educação superior.

\section{REFERÊNCIAS}

BARREYRO, G. B. Do Provão ao SINAES: o processo de construção de um novo modelo de avaliação da educação superior. Avaliação: revista da Rede de Avaliação Institucional da Educação Superior - RAIES, Campinas, SP, v. 8, n. 4, p. 37-49, 2003.

BRASIL. Constituição (1988). Constituição da República Federativa do Brasil. São Paulo: Imprensa Oficial do Estado de São Paulo, 1999.

BRASIL. Decreto n. ${ }^{\circ}$ 2.026, de 10 de outubro de 1996. Estabelece procedimentos para o processo de avaliação dos cursos e instituições de ensino superior. Diário Oficial[ da] República Federativa do Brasil, Brasília, DF, 11 out. 1996a. Seção 1, p. 20545. 
BRASIL. Decreto n.3.860, de 9 de julho de 2001. Dispõe sobre a organização do ensino superior, a avaliação de cursos e instituições e dá outras providências. Diário Oficial[ da] República Federativa do Brasil, Brasília, DF, 10 jul. 2001.

BRASIL. Lei n.9.394, de 20 de dezembro de 1996. Estabelece as diretrizes e bases da educação nacional. Diário Oficial[ da] República Federativa do Brasil, Brasília, DF, 23 dez. $1996 b$.

BRASIL. Lei $n^{\circ} .10 .861$, de 14 de abril de 2004. Institui o Sistema Nacional de Avaliação da Educação Superior - SINAES. Diário Oficial[ da] República Federativa do Brasil, Brasília, DF, 15 abr. 2004a. Seção 1.

BRASIL. Portaria n ${ }^{\circ}$ 249, de 18 de março de 1996. Institui a sistemática para a realização do Exame Nacional de Cursos. Diário Oficial[ da] República Federativa do Brasil, Brasília, DF, 20 mar. 1996c. Seção 1, p. 4686.

BRASIL. Ministério da Educação. Comissão Nacional de Avaliação. SINAES: bases para uma nova proposta de avaliação da educação superior brasileira. Brasília, 2004b.

BRASIL. Ministério da Educação e do Desporto. Secretaria de Educação Superior. Programa de Avaliação Institucional das Universidades Brasileiras. Brasília, DF, 1994.

BRASIL. Ministério da Educação. Instituto Nacional de Estudos e Pesquisas Educacionais Anísio Teixeira. Portaria $n^{\circ} 108$, de 22 de julho de 2004. Institui a sistemática para a aplicação do Exame Nacional de Desempenho dos Estudantes -ENADE. Diário Oficial [da] República Federativa do Brasil, Brasília, DF, 23 jul. 2004c. Seção 1.

INSTITUTO NACIONAL DE ESTUDOS E PESQUISAS EDUCACIONAIS ANÍSIO TEIXEIRA. Resumo técnico do Exame Nacional de Cursos. Brasília, DF, 2003.

MARINHO-ARAUJO, C. M. O desenvolvimento de competências no ENADE: a mediação da avaliação nos processos de desenvolvimento psicológico e profissional. Avaliação: revista da Rede de Avaliação Institucional da Educação Superior, Campinas, SP, v. 9, n. 4, p. 77-97, 2004.

POLIDORI, M. M. Avaliação do ensino superior: uma visão geral e uma análise comparativa entre os contextos brasileiro e português. 2000. 547 f. Tese (Doutorado)- Faculdade de Psicologia e de Ciências da Educação, Universidade do Porto, Porto, PT, 2000.

Recebido: 24/06/2005

Aceito para publicação: 18/09/2006 